\title{
The Longer Term Outcomes of Community Care: A twelve year follow-up of the Camberwell High Contact Survey
}

June 2000

Authors: Yael Reid ${ }^{1}$, *Sonia Johnson ${ }^{2}$, Paul Bebbington ${ }^{2}$, Elizabeth Kuipers ${ }^{1}$, Helen Scott ${ }^{3}$ and Graham Thornicroft ${ }^{1}$

${ }^{1}$ Institute of Psychiatry, London, UK, ${ }^{2}$ Department of Psychiatry and Behavioural Medicine, Royal Free and University College Medical Schools, ${ }^{3}$ Sainsbury Centre for Mental Health

*address for correspondence:

S. Johnson

Department of Psychiatry and Behavioural Sciences,

Royal Free and University College London Medical Schools

University College London

48 Riding House Street

London, WIN 8AA

E-mail: s.johnson@ucl.ac.uk 


\begin{abstract}
Background: There is as yet little evidence available regarding the long-term outcomes of people with severe and enduring mental illness who have been cared for primarily in the community.
\end{abstract}

Methods: A twelve year follow-up was carried out of the clinical and social problems and needs for care of a group of long-term mentally ill patients $(n=81)$ who were heavy users of psychiatric services when originally assessed in the Camberwell High Contact Survey between 1983 and 1985. The Needs for Care Assessment Schedule used in the original baseline study was repeated at follow-up.

Results: The clinical and social functioning of the group had remained relatively stable, with high levels of problems and needs at both time points and little evidence of significant improvement or deterioration. The majority had remained in contact with services. There was some increase in levels of unmet as well as met needs, and a decrease in ratings of unmeetable needs, which may have been due to changes in clinical practice.

Conclusion: The challenge for current service providers is not only to keep clients stable, but also to help improve the clinical and social functioning of people who may no longer be the highest priority of current community mental health services. This could be approached by identifying the continuing needs of this group, and persistently delivering active treatments. 


\section{$\underline{\text { Introduction }}$}

Mental health services in the UK have been evolving towards a more communitybased model since the 1950s, with the closure of the large mental hospitals and progressive development of out-patient services, day hospitals, day centres, community psychiatric nurse services and, latterly, multidisciplinary community mental health teams (Freeman \& Bennett 1991). Thus there are many individuals with severe and enduring mental illness who are now approaching old age and have spent much of their lives living in the community and using community-based services. Although several studies have examined outcomes over periods of around one to two years for individuals using particular, often innovative, services (e.g Muijen et al., 1992, Tyrer et al., 1998, Burns et al., 1993) there is a lack of information about the long-term effects of community-based mental health care. Longer term follow-up is especially important in view of the long duration of disabilities of individuals with enduring mental health problems. The Camberwell High Contact Survey focused on the met and unmet needs for care of a group of high service users: subjects were severely mentally ill individuals who were engaged with community-based services, particularly in day care settings, between 1983 and 1985 (Brewin et al., 1987., 1988, Brugha et al., 1988). The availability of these data provides an excellent opportunity to trace the subsequent progress of this cohort and their outcomes over the intervening period, a period during which a further evolution has occurred in service models towards home-based care and community-based multidisciplinary teams.

One of the few other sources of evidence on longer term outcomes of community mental health care in the UK is the study carried out in Nottingham in which an 
epidemiologically defined and representative cohort of patients was followed up over 13 years (Mason et al., 1996, Harrison et al., 1994). They had originally been identified in 1978-80 when they were experiencing their first episode of psychosis. At follow up, half of the sample had experienced no positive psychotic symptoms in the previous two years and half showed no evidence of negative symptoms. Just over half showed fair to good levels of social functioning. However, the proportion free from symptoms or disability and not currently receiving psychotropic medication was only 17\%. Kelly et al. (1998) report a fifteen year follow-up of a population of patients with schizophrenia in contact with Crichton Royal Hospital in Scotland in 1981. At follow-up, more patients were found to have positive and negative symptoms and tardive dyskinesia than at the initial assessment. Social adjustment had not changed significantly.

The distinctive features of the current study are that most of the cohort already had very substantial histories of mental illness at the time of the initial interview and that the main means of assessment at baseline and follow-up was based on needs for care. At both timepoints, a systematic needs assessment procedure which had been developed specifically for the original study, the MRC Needs for Care Assessment (Brewin et al., 1987, Brewin 1992), was applied. This procedure is briefly outlined in the 'methods' section below.

Brugha et al. (1988) have described the characteristics of the original sample and the care they were receiving in some detail. About one fifth of the sample had stayed in hospital for a year or more on at least one occasion in the past. None were in paid employment, and a substantial proportion had general health problems and disabilities 
in addition to considerable clinical and social difficulties. All were attending day care facilities in Camberwell, some at the Maudsley Hospital, others at a range of other NHS and local authority sites in the London Borough of Southwark. Brewin et al. (1988) reported the problems and needs for care of this sample. The mean number of clinical problems identified for subjects in the sample was 2.8 and the mean number of social problems 4.3. Since the original survey, the Needs for Care Assessment has been used internationally amongst a variety of different patient groups (see Wiersma et al., 1996 for review). The mean number of clinical problems in these settings varied between 2.1 (Groningen (Honkonen, 1995), Verona (Lesage et al., 1991)) and 3.9 (Montreal (van Haaster et al, 1994) and that of social problems between 1.7 (Verona) and 7.8 (South Glamorgan (Pryce et al. 1993)).

Whilst members of the High Contact Study cohort were already receiving communitybased care at the beginning of the twelve year follow-up period, a variety of changes had taken place in this type of care by the time of follow-up. Rehabilitative day care was the focus of considerable interest in the UK at the time of the original study (Watts and Bennett 1983), and the District Services Centre at the Maudsley, used by some of those in the sample, had recently opened as a model day care service specifically tailored to the needs of this group of individuals with chronic and severe mental health problems. Since that time, the emphasis in UK mental health provision appears to have shifted rather more towards the creation of community mental health teams and home-based care. There has been particular concern with the needs of young, difficult to engage individuals who have never experienced institutionalisation, often misuse substances, and may present a significant risk of harm to themselves or, in particular, others (Sainsbury Centre, 1998). A question which needs to be addressed 
is whether, with this shift in focus, the needs of the group of older long-term clients who were previously engaged in day care services are adequately catered for. Tracing and re-interviewing the Camberwell High Contact cohort allowed us to examine the course over more than a decade of such a group and the extent to which their needs for care have been met.

\section{Method}

\section{Original sample}

In brief, the original sample consisted of 145 patients aged 18 years or over who were living in South Southwark, attended a psychiatric day hospital or a day centre, and had been in contact with local mental health services for at least one year. In-patients, patients with severe retardation, patients addicted to substances other than alcohol, and patients over 65 years of age suffering from dementia were excluded. Approximately half of the sample had received a hospital diagnosis of schizophrenia or paranoid psychosis. The mean number of years since first contact with psychiatric services was 17 years for men and 14 years for women.

\section{$\underline{\text { Initial assessments (1985) }}$}

The MRC Needs for Care Assessment (NFCAS) was used to assess needs. This involves making ratings for nine 'clinical' and twelve 'social' aspects of symptoms and functioning (see table 3), with best available information obtained from patients and staff and any other available sources using a variety of structured assessments. A panel of clinicians from different disciplines including psychiatry, clinical psychology and social work met to consider the problem and need status of each of the nine clinical and twelve social areas assessed. Where there was evidence of a threatened, 
recent or current symptom or a deficit in social functioning, the patient was rated as having a problem in the area concerned, and enquiries were made into the provision of relevant interventions. The assessment included guidelines for judging the appropriateness of various interventions. If a need had attracted an intervention that was at least partly effective, it was described as a 'met' need. If no intervention was being carried out at all or the intervention was ineffective, the need was described as 'unmet'. The remaining category was one of 'overmet' need, (ie if the intervention was removed the patient would not deteriorate). Inter-rater reliability has been investigated by Brewin et al., (1987), Lesage et al., (1991), Holloway (1991) and Van Haaster et al., (1994 a, b) and found to be excellent.

\section{Follow-up study}

\section{$\underline{\text { Tracing }}$}

Subjects were traced through several sources: the day centres or hospitals attended at the time of the previous study; local hospital and community mental health teams; and general practitioners and various family health services authorities throughout the country. Patients who were still in contact with the psychiatric services were approached for interview via their consultant or keyworker.

\section{$\underline{\text { Follow-up assessments }}$}

We aimed to replicate the NFCAS procedure as closely as possible. Information was obtained from a variety of sources including patients, staff and case notes. Ratings of 
problem and need status were agreed by consensus in a group including two psychiatrists, a clinical psychologist and two research psychologists. The research team decided that the concept of 'no meetable need' (areas where there was a substantial problem but no intervention that appeared likely to work) was a useful one and, as in the more recent versions of the NFCAS, needed to be distinguished from 'met need'. In the original version, though not in the later revised version, these two categories were conflated. There was sufficient information in the original data set to separate out 'met need' and 'no meetable need', and we did this prior to carrying out our analyses.

\section{Analysis}

Analysis was carried out using SPSS for Windows (version 6.0). Paired sample t- tests were used to assess changes in the overall numbers of problems, and of met and unmet needs between baseline and follow-up. Differences in specific problems and needs in each clinical and social area between time one and time two were assessed with McNemar tests which indicates the extent to which individuals have the same problems at the two time points. Stepwise multiple regression analysis (using SPSS default values for entry and exit of variables) was used to examine associations between clinical and demographic factors and the extent of changes in total number of problems and total number of unmet needs since baseline. The dependent variables were the change in the number of problems and of unmet needs, the independent variables entered into the model were age, sex, diagnoses, negative symptoms at baseline, social network at baseline, years in contact with psychiatric services, 
(outpatient and CPN services ), number of years in day care, years in inpatient care, years in independent living, and years in supported accommodation.

\section{$\underline{\text { Results }}$}

We were able to obtain follow-up information on 81 individuals from the original sample of 145. Thirty-six were known to have died and 28 could not be traced. Seventy individuals had full assessments (including personal interviews), and for a further 11 there was enough information available from records and informants to complete the needs for care assessment, even though we had not succeeded in interviewing them.

Comparisons were made between the group followed up and those whom we were unable to assess the follow-up point on the main initial socio-demographic indicators, the NFCAS data, and also results of the Social Behaviour Schedule (SBS, Wykes and Sturt, 1998). Not surprisingly, the group not assessed at follow up were older (56 years vs. 45 years at the original assessment, $\mathrm{t}=5.1, \mathrm{p}=0.000$ ). The group whom we followed up did not differ significantly at the $\mathrm{p}=0.05$ level from the rest in gender distribution (53\% of those followed up and $56 \%$ of the rest were male), proportion who were married or cohabiting ( $19 \%$ of those followed up, $22 \%$ of the remainder), proportion born outside Europe (19\% of those followed up, $16 \%$ of the rest), or proportion in supported accommodation (27\% of those followed up, $30 \%$ of the rest). The proportion with an initial diagnosis of schizophrenia was slightly higher in the group successfully followed up (43\%) than in the remainder (31\%). On the NFCAS, the mean total number of problems was greater for those not assessed at follow up 
(mean of 7.6 vs. 6.0 problems, $\mathrm{p}=0.002$ ), reflecting a greater number of social problems ( 4.8 vs. $3.3, \mathrm{p}=0.04)$, but not of clinical problems ( 2.9 vs. $2.6, \mathrm{p}=0.2)$. The areas in which those not followed up were significantly more likely to have a problem were cooking, shopping, personal hygiene, public transport, household chores, use of public amenities and physical health, some or all of which may have been related to the greater age of this group. However, no significant differences were found in levels of clinical and social unmet needs, in total Social Behaviour Schedule score or in score for any of the SBS sub-scales (social problems, behaviour problems, negative symptoms and neurotic symptoms).

Insert table I

The mean age of the sample on whom data could be obtained at follow-up was 56 years, and $54 \%$ were male. Table 1 shows the changes in the settings of care and living arrangements from baseline for this group. The proportion living in sheltered accommodation had risen since follow-up, whilst fewer of the sample lived with parents. Only half of the sample (51\%) were currently attending day care regularly. Of the $51 \%$ who were currently regular day care attenders, $58 \%$ had attended continuously for at least 5 years (without a break of more than three months). Of those not attending day care currently, half had ended around two years previously. Meanwhile, the proportion in contact with a CPN or another member of a multidisciplinary mental health team other than a psychiatrist had risen from $5 \%$ to $64 \%$. The majority (69\%) were seen regularly by a psychiatrist. Eighty-four percent had contact with some form of secondary mental health service, via an out-patient clinic, contact with a member of a multi-disciplinary community team or both. Forty percent 
of the sample were regularly in contact with their G.P for mental health care. Ten percent were only in contact with primary care services and no secondary services. Only $6 \%$ were not in regular contact with psychiatric or primary care services.

Insert table II

Table II shows the mean number of problems, and of met and unmet needs at the original interview and at follow-up. The total number of clinical and social problems (6.22) had not changed significantly from the original total number of problems per individual of 5.95. Overall, the average number of met needs was higher at follow-up ( $\mathrm{p}=0.001$ ), due particularly to an increase in social met needs between time 1 and time $2(\mathrm{p}=0.001)$. The number of unmet needs had also increased slightly at follow-up, but only for clinical unmet needs $(\mathrm{p}=0.04)$. There was a substantial reduction in the mean number of unmeetable needs from an average of 2.65 at time 1 to 1.33 at time 2 $(\mathrm{p}=0.0001)$.

\section{Changes in problems between first interview and follow-up}

At baseline the most commonly occurring problems in the month before interview were positive psychotic symptoms, occupational skills, social skills/interaction, and side effects. At follow-up the commonest problems were positive symptoms, occupational skills, physical disorders, and neurotic symptoms.

Insert table III 
Table III shows the changes in the patterns of clinical and social problems over the follow-up. Asterisks indicate those problems for which a significant difference in distribution (at the $\mathrm{p}=0.05$ level) between time 1 and 2 was detected using McNemar's test. There was a significant reduction in problems with social skills $(\mathrm{p}=0.0001)$ and decision making $(\mathrm{p}=0.0027)$ between first interview and follow-up. However, there was a significant increase in problems with neurotic symptoms $(\mathrm{p}=0.023)$; physical disease $(\mathrm{p}=0.045)$; personal hygiene $(\mathrm{p}=0.001)$ and use of public transport $(\mathrm{p}=0.002)$.

\section{Changes in unmet needs between first interview and follow-up}

Insert table IV

Table IV shows the changes in the patterns of clinical and social unmet needs over the follow-up period. At baseline, unmet needs were most frequent in the areas of neurotic symptoms, positive psychotic symptoms, and education. At follow-up, unmet needs occurred most frequently in relation to positive symptoms, occupational skills, and education. There were no statistically significant differences in the distribution of unmet needs in individual problem areas per individual between time 1 and 2 as assessed with McNemar tests.

$\underline{\text { Regression analysis examining factors associated with degree of change in problems }}$ and unmet needs

Stepwise multiple regression with extent of change in total number of unmet needs as dependent variable indicated that the following independent variables appeared to be 
associated with an increase in the level of unmet needs over the follow-up period: greater proportion of years since initial interview spent out of contact with psychiatric services over follow-up period $(\mathrm{p}=0.004)$, presence of negative symptoms at initial assessment $(\mathrm{p}=0.001)$, and an initial diagnosis which was not depression, anxiety or personality disorder $(\mathrm{p}=0.007)$. Adjusted $\mathrm{R}^{2}$ for this regression was 0.30 . No variables were significantly associated with the extent of change in number of problems over the follow-up period.

\section{$\underline{\text { Discussion }}$}

The NFCAS has some significant limitations. It is based on a specific model of psychiatric rehabilitation which is problem-focused and skills-oriented. Whilst patients' and carers' views are taken into account, the minimum levels of functioning below which a need is identified are essentially stipulated by experts, and assessment of whether functioning does fall below these levels and of what interventions might be useful and feasible is also mainly by experts. The instrument also focuses only on needs related to specific symptoms or impairments in functioning, taking little account of more general needs such as for adequate housing and welfare provision or for company. Whilst we tried to replicate as closely as possible the original procedure and approach to assessment, it is likely that changes in clinical practice in the intervening years have shaped views about appropriate intervention for particular problems. For example, atypical antipsychotics and new developments in cognitive-behavioural therapy have significantly extended the range of possible approaches to persistent positive symptoms of psychosis. Overall, however, the marked similarities between patterns found at the two timepoints seems to suggest there may well have been 
reasonable reliability in making assessments. A further limitation of the study was that we were unable to trace all the members of the original cohort. The main respects in which those followed up appear to have been dissimilar from the rest are younger age and, perhaps associated with this, lower rates of problems with physical health and daily living activities such as shopping, cooking and household chores.

Despite these drawbacks, this is the first study that has used an assessment of need as the basis of a long-term follow-up. It thus allows assessment not only of the course of the clinical and social problems of a group of chronically disabled people, but also of the adequacy of the response of services to these problems.

Overall, the clinical and social functioning of our cohort had remained remarkably static over the twelve year period of the study. Both initially and at follow-up, our sample had a higher overall level of problems than found amongst patients in various health care settings internationally (e.g Lesage et al., 1991; Wiersma et al., 1996; Middleton et al., 1996). This is almost certainly the result of the initial selection criteria: almost all had established chronic illnesses and had been in contact with services for ten years or more. A substantial proportion already had general health problems and disabilities, and none were in paid employment. The problems of this group may also have been compounded by living in a deprived inner city area where social isolation is likely to be common.

The picture of community care that emerges from this study suggests that it has had some limited benefits. Spending more time in contact with services was associated with fewer unmet needs at follow-up, suggesting that individuals may have been better 
off in contact than not. There was certainly no dramatic deterioration in symptoms or functioning in our sample, but neither was there much resolution of long-standing problems, with a marked tendency in many clinical and social areas for problems to persist over the twelve years of follow up. Areas in which individuals were more likely to have problems at follow-up than at baseline were neurotic symptoms, personal hygiene, physical disease, and the use of public transport. The latter two are not surprising, given the increasing age of our sample. However, improvements were evident in the area of social skills. This may have been as a result of experience obtained in social interaction through prolonged community residence, and suggest a degree of success for community-based care.

Some slight shifts were detected in levels of needs, which were still generally high. There was evidence of increases in total number of both met and unmet needs, most noticeably in the area of clinical needs. Unmeetable needs had decreased (needs are defined as unmeetable when a potentially effective intervention is not available or is being refused by the patient) whilst unmet needs had increased. As discussed above, this shift may particularly relate to new interventions for the treatment of previously drug resistant psychotic symptoms. The research team were unwilling to make a rate of unmeetable need for intervention with psychotic symptoms unless these strategies had been tried. This is likely to have led to more ratings of unmet clinical need and fewer of unmeetable need than would have been the case in the context of the routine clinical practice of the early 1980s.

Overall, however, stability in problems and needs is much more striking than any changes detected. Because the problems were very long-term, expectations of 
improvement must in any case be limited. One might, however, have hoped that services would have been able to reduce unmet needs to a very low level, and might over time have shown greater improvement.

In considering why evidence of improvement was so limited, one may note that under current community care policy, the focus of care has moved away from the provision of structured day care towards the creation of generic community mental health teams (subjects were far more likely at follow-up to be in contact with a member of such a team), The work of these teams tends to emphasise prevention and management of crises and support at home for highly vulnerable individuals who are at risk of harming themselves or others or of disengaging from services. The group we studied are not the very non-compliant and challenging patients who tend to be given highest priority in service provision with recent legislative measures such as the supervision register (NHS Executive, 1994) or in much discussed service developments such as assertive outreach (Sainsbury Centre, 1998). On the whole the aging cohort followed up in our study are a more stable group who nonetheless have significant and enduring symptoms and disabilities. It is important that the needs of this group are not overlooked as concern regarding risk runs high and the emphasis in service planning shifts away from facilities such as long term day care towards services such as community mental health, assertive outreach and crisis intervention teams. There was a trend, though not one reaching statistical significance, towards an increase in unmet needs for intervention in the area of occupational skills, and it is possible that this reflects the lower levels of day care provision for this group. Service providers also need to consider what forms of intervention should be available from community services for this group with longer term needs. Generic community mental health 
teams routinely keep in touch with people and monitor them, thus maintaining some degree of stability. However, actually improving outcomes may require the development and application of active treatment strategies, such as cognitive treatment for psychosis or family therapy, as well as the development and dissemination of the more traditional rehabilitation techniques (Hughes et al. 1996) which have been discussed little in recent UK literature on mental health service development and evaluation and may now be somewhat in abeyance.

\section{$\underline{\text { Acknowledgements }}$}

We are grateful to Dr. Morven Leese for advice on the statistical analysis and to the authors of the original Camberwell High Contact Study for permission to use their data as the basis of this follow-up. 


\section{$\underline{\text { References: }}$}

Brugha, T.S., Wing, J.K., Brewin, C.R., MacCarthy, B., Mangen, S., Lesage. A. and Mumford .J. (1988) The Problems of people in long-term psychiatric day care. An introduction to the Camberwell High Contact Survey. Psychological Medicine 18, 18, $443-446$

Brewin, C.R., Wing, J.K., Mangen, S.P., Brugha, T.S. and MacCarthy, B. (1987)

Principles and practice of measuring needs in the long-term mentally ill: the MRC Needs for Care Assessment. Psychological Medicine 17:971-981

Brewin, C.R., Wing, J.K., Mangen, S.P., Brugha, T.S, and MacCarthy, B. (1988) Needs for Care among the long-term mentally ill: a report from the Camberwell High Contact Survey. Psychological Medicine 18: 457-468

Brewin, C. R. (1992) Measuring individual needs for care and services. In Measuring Mental Health Needs (Eds Thornicroft. G., Brewin. C. R. and Wing. J.K). Gaskell Royal College of Psychiatrists, London

Burns, T., Raftery, J., Beadsmore, A., McGuigan, S. and Dickson, M. (1993) A controlled trial of home-based acute psychiatric services II. Treatment patterns and costs. British Journal of Psychiatry 163: 55-61 
Freeman, H.L \& Bennett, D.H (1991) Community Psychiatry. The principles. Churchill. Livingstone. London .

Harrison, G., Mason, P., Glazebrook, C., Medley, I., Croudace, T. and Docherty, S. (1994) Residence of incident cohort of psychotic patients after 13 years of follow-up. British Medical Journal 303: 813-6

Holloway, F., (1991) Day care in an inner city II. Quality of the services. British Journal of Psychiatry 158: 810-816

Honkonen, T. (1995) Need for care and support in schizophrenia. A follow-up study of discharged schizophrenic patients. Academic dissertation. University of Tampere, Finland. (cited Wiesma et al. 1996)

Hughes, R., Lehman, A. and Arthur, R. (1996) Psychiatric rehabilitation. In Breakey, W. (ed) Integrated mental health services: modern community psychiatry. New York, Oxford University Press.

Kelly, C., McCreadie, G., MacEwan., and Carey. S. (1998) Nithsdale Schizophrenia Surveys 17. Fifteen year review. British Journal of Psychiatry 172, 513-517

Lesage, A.D., Mignolli,. G., Faccincani, C. and Tansella, M. (1991) Standardised assessment of the needs for care inh a cohort of patients with schizophrenic psychoses. In Community-based Psychiatry : Long-term Patterns of Care in South-Verona (ed M. Tansella), pp 27-34. Cambridge University Press: Cambridge. 
Mason, P., Harrison, G., Glazebrook, C., Medley, I., Dalkin.T. and Croudace. T. (1995) The course of schizophrenia over 13 years: a report from the International Study on Schizophrenia (ISoS) co-ordinated by the World Health Organisation. British Journal of Psychiatry 167 (5): 596-603

Middleton, H., Hugh, C., Regueira., Manual, F. and Bramley, M. (1996) Formal needs assessment: An application of the MRC Needs for Care Assessment Schedule. Journal of Mental Health Vol 5 (1) 65-75

Muijen, M., Marks.M., Connolly. J., Audini. B. and McNamee. G. (1992). Preliminary Comparison of Community Versus Hospital-Based Treatment for the Seriously Mentally Ill Facing Emergency Admission. British Journal of Psychiatry $160,379-384$.

NHS Executive (1994) Introduction of supervision registers for mentally ill people from 1 April 1994. London, HMSO.

Pryce, I.G., Griffins, R.D., Gentry, R.M., Hughes, ICT, Montague, L.R., Watkins, S.E., Champey-Smith. J. and McLackland. B.M. (1993) The nature and severity of disabilities in long-stay psychiatric in-patients in South Glamorgan. British Journal of Psychiatry 158: 817-821

Sainsbury Centre for Mental Health (1998) Keys to engagement. London: Sainsbury Centre for Mental Health 
Tyrer, P., Evans, K., Ghandhi, N., Lamont, A., Harrison-Reid.P. and Johnson T. (1998) Randomised controlled trial of two models of care for discharged psychiatric patients British Medical Journal 316: 109

van Haaster, I., Lesage, A. D., Cyr. M. and Toupin, J. (1994b) Problems and needs for care of patients suffering from severe mental illness. Social Psychiatry and Psychiatric Epidemiology 29: 141-148

Watts, F. and Bennett, D.H (1991) Theory and practice of psychiatric rehabilitation. Wiley: Chichester. U.K.

Wiersma, D., Giel.R., de Jong. A., Nienhuis, F.J. and Sloof. C.J. (1996) Assessment of the need for care 15 years after onset of a Dutch cohort of patients with schizophrenia, and an international comparison Social Psychiatry and Psychiatric Epidemiology 31: 114-121

Wykes, T. and Sturt, E. (1986) The measurement of social behaviour in psychiatric patients: an assessment of the reliability and validity of the SBS schedule. British Journal of Psychiatry 148: 1-11 
Table I- Care and living circumstances at baseline and follow-up for the subjects assessed at both time points. $(\mathrm{N}=81)$

\begin{tabular}{|l|l|l|}
\hline & $1983 / 5$ & $1995 / 6$ \\
\hline Living alone & $24(30 \%)$ & $18(23 \%)$ \\
Living with partner & $16(20 \%)$ & $20(25 \%)$ \\
Living with parents & $13(16 \%)$ & $3(4 \%)$ \\
Supported accommodation & $21(26 \%)$ & $37(46 \%)$ \\
In hospital & $5(6 \%)$ & $2(3 \%)$ \\
Day care attender & $81(100 \%)$ & $41(51 \%)^{*}$ \\
Contact with member of & $5(6 \%)$ & $51(64 \%)$ \\
mental health team other & & \\
than psychiatrist & & \\
\hline
\end{tabular}

Mean length of day care in follow up period- 8 years

$* 25 \%$ of cohort- day care stopped two years ago 
Table II Mean numbers of problems, and unmet needs at baseline (time1) and followup (time 2) per subject- paired sample t-tests $(n=81)$

\begin{tabular}{|l|l|l|l|l|}
\hline & Time one & $\begin{array}{l}\text { Time } \\
\text { two }\end{array}$ & $\boldsymbol{t}$ & $\boldsymbol{p}$ \\
\hline Mean total no. of problems & 5.95, & 6.22 & & \\
(standard deviation (S.D)., & $(3.05$, & $(3.81$, & -0.61 & 0.545 \\
range (minimum no.- & $0-13)$ & $0-16)$ & & \\
maximum no.)) & & & & \\
\hline Mean no. of social & 3.35 & 3.41 & -1.6 & 0.87 \\
problems & $(2.51$, & $(3.15$, & & \\
(S.D., range) & $0-10)$ & $0-12)$ & & \\
\hline Mean no. of clinical & 2.60 & 2.81 & -1.17 & 0.244 \\
problems & $(1.36$, & $(1.46$, & & \\
(S.D., range) & $0-6)$ & $0-6)$ & & \\
\hline * Mean total no. of unmet & 1.07 & 1.59 & 2.26 & 0.027 \\
needs & $(1.28$, & $(2.01$, & & \\
(S.D., range) & $0-5)$ & $0-12)$ & & \\
\hline Mean no. of social unmet & 0.59 & 0.87 & -.1 .74 & 0.085 \\
needs & $(0.96$, & $(1.35$, & & \\
(S.D., range) & $0-4)$ & $0-8)$ & & \\
\hline * Mean no. of clinical & 0.48 & 0.76 & -.2 .03 & 0.046 \\
unmet needs & $(0.69$, & $(1.0$, & & \\
(S.D., range) & $0-3)$ & $0-4)$ & & \\
\hline *Mean total no. of met & 2.26 & 3.31 & -3.49 & 0.001 \\
needs & $(1.75$, & $(2.26$, & & \\
(S.D., range) & $0-7)$ & $0-8)$ & & \\
\hline Mean no. of met clinical & 1.38 & 1.59 & -1.11 & 0.27 \\
needs & $(1.18$, & $(1.35$, & & \\
(S.D., range) & $0-5)$ & $0-5)$ & & \\
\hline *Mean no. of met social & 0.88 & 1.72 & -3.56 & 0.001 \\
needs & $(1.12$, & $(1.93$, & & \\
(S.D., range) & $0-6)$ & $0-7)$ & & \\
\hline *Mean total no. of & 2.65 & 1.33 & 5.89 & 0.0001 \\
unmeetable needs & $(2.05$, & $(1.56$, & & \\
(S.D., range) & $0-8)$ & $0-6)$ & & \\
\hline
\end{tabular}

*significantly different at $p=0.05$ 
Table III Changes in patterns of clinical \& social problems over the follow-up period. Chisquared tests

${ }^{*}$ significant differences at $p=0.05$ level

\begin{tabular}{|l|l|l|l|l|l|}
\hline Problem area & $\begin{array}{l}\text { Total number } \\
\text { of problems } \\
\text { at time one }\end{array}$ & $\begin{array}{l}\text { Total } \\
\text { number of } \\
\text { problems at } \\
\text { time two }\end{array}$ & $\begin{array}{l}\text { \% of subjects } \\
\text { with a problem at } \\
\text { time 2 who had a } \\
\text { problem at time 1 }\end{array}$ & $\begin{array}{l}\text { \% of subjects with a } \\
\text { problem at time 1 } \\
\text { who have a problem } \\
\text { at time 2 }\end{array}$ & $\begin{array}{l}\text { p } \\
\text { McNemar } \\
\text { Test }\end{array}$ \\
\hline
\end{tabular}

\section{Clinical problems}

\begin{tabular}{|l|l|l|l|l|l|}
\hline $\begin{array}{l}\text { Positive } \\
\text { symptoms }\end{array}$ & $53(66 \%)$ & $60(75 \%)$ & $47(78 \%)$ & $47(89 \%)$ & .167 \\
\hline $\begin{array}{l}\text { Negative } \\
\text { symptoms }\end{array}$ & $18(23 \%)$ & $16(20 \%)$ & $9(56 \%)$ & $9(50 \%)$ & .804 \\
\hline Side effects & $30(37 \%)$ & $25(30 \%)$ & $15(60 \%)$ & $15(50 \%)$ & .424 \\
\hline $\begin{array}{l}\text { * Neurotic } \\
\text { symptoms }\end{array}$ & $23(29 \%)$ & $35(44 \%)$ & $17(48 \%)$ & $17(74 \%)$ & .023 \\
\hline $\begin{array}{l}\text { Organic brain } \\
\text { disease }\end{array}$ & $2(3 \%)$ & $5(7 \%)$ & $1(20 \%)$ & $1(50 \%)$ & .375 \\
\hline $\begin{array}{l}\text { *Physical } \\
\text { disorders }\end{array}$ & $27(33 \%)$ & $39(48 \%)$ & $18(46 \%)$ & $18(67 \%)$ & .045 \\
\hline $\begin{array}{l}\text { Violence to } \\
\text { self/others }\end{array}$ & $15(19 \%)$ & $18(22 \%)$ & $7(39 \%)$ & $7(47 \%)$ & .648 \\
\hline $\begin{array}{l}\text { Embarrassing } \\
\text { behaviour }\end{array}$ & $18(23 \%)$ & $13(16 \%)$ & $6(50 \%)$ & $6(33 \%)$ & .238 \\
\hline Distress & $21(27 \%)$ & $19(24 \%)$ & $5(26 \%)$ & $5(24 \%)$ & .855 \\
\hline
\end{tabular}

\section{Social problems}

\begin{tabular}{|l|l|l|l|l|l|}
\hline $\begin{array}{l}{ }^{*} \text { Personal } \\
\text { Cleanliness }\end{array}$ & $5(6 \%)$ & $16(20 \%)$ & $5(31 \%)$ & $5(100 \%)$ & .001 \\
\hline Shopping & $10(13 \%)$ & $20(25 \%)$ & $3(15 \%)$ & $3(30 \%)$ & .639 \\
\hline $\begin{array}{l}\text { Cooking/ } \\
\text { getting meals }\end{array}$ & $10(13 \%)$ & $20(25 \%)$ & $3(15 \%)$ & $3(30 \%)$ & .648 \\
\hline $\begin{array}{l}\text { Household } \\
\text { chores }\end{array}$ & $11(15 \%)$ & $14(19 \%)$ & $3(21 \%)$ & $3(27 \%)$ & .664 \\
\hline $\begin{array}{l}{ }^{*} \text { Public } \\
\text { transport }\end{array}$ & $3(4 \%)$ & $16(21 \%)$ & $1(6 \%)$ & $1(33 \%)$ & .002 \\
\hline $\begin{array}{l}\text { Public amenities } \\
\text { Education }\end{array}$ & $8(10 \%)$ & $15(19 \%)$ & $1(7 \%)$ & $1(13 \%)$ & .189 \\
\hline $\begin{array}{l}\text { Occupational } \\
\text { skills }\end{array}$ & $47(70 \%)$ & $82(78 \%)$ & $35(67 \%)$ & $3(29 \%)$ & .189 \\
\hline $\begin{array}{l}\text { * Social } \\
\text { interaction }\end{array}$ & $37(46 \%)$ & $17(21 \%)$ & $13(77 \%)$ & $13(35 \%)$ & .458 \\
\hline $\begin{array}{l}\text { Management } \\
\text { of money }\end{array}$ & $25(32 \%)$ & $24(30 \%)$ & $10(42 \%)$ & $10(40 \%)$ & .0001 \\
\hline $\begin{array}{l}\text { Management of } \\
\text { affairs }\end{array}$ & $35(46 \%)$ & $42(55 \%)$ & $25(60 \%)$ & $25(71 \%)$ & .000 \\
\hline $\begin{array}{l}{ }^{*} \text { Decision } \\
\text { making }\end{array}$ & $36(46 \%)$ & $18(23 \%)$ & $11(61 \%)$ & $11(31 \%)$ & .0027 \\
\hline
\end{tabular}

Table IV Changes in patterns of clinical and social unmet needs over the follow-up period. 


\begin{tabular}{|c|c|c|c|c|c|}
\hline Problem area & $\begin{array}{l}\text { Total number } \\
\text { of unmet } \\
\text { needs at time } \\
\text { one }\end{array}$ & $\begin{array}{l}\text { Total } \\
\text { number of } \\
\text { unmet } \\
\text { needs at } \\
\text { time two } \\
\end{array}$ & $\begin{array}{l}\% \text { of subjects } \\
\text { with unmet needs } \\
\text { at time } 2 \text { who had } \\
\text { unmet needs at } \\
\text { time } 1\end{array}$ & $\begin{array}{l}\text { \% of subjects with } \\
\text { unmet needs at time } \\
1 \text { who have unmet } \\
\text { needs at time } 2\end{array}$ & $\begin{array}{l}\mathrm{p}= \\
\text { McNemar } \\
\text { Test }\end{array}$ \\
\hline \multicolumn{6}{|l|}{ Clinical problems } \\
\hline $\begin{array}{l}\text { Positive } \\
\text { symptoms }\end{array}$ & $10(12 \%)$ & $15(19 \%)$ & $4(27 \%)$ & $4(40 \%)$ & .332 \\
\hline $\begin{array}{l}\text { Negative } \\
\text { symptoms }\end{array}$ & $2(3 \%)$ & $5(6 \%)$ & 0 & 0 & .453 \\
\hline Side effects & $3(4 \%)$ & $7(9 \%)$ & $1(14 \%)$ & $1(33 \%)$ & .289 \\
\hline $\begin{array}{l}\text { Neurotic } \\
\text { symptoms }\end{array}$ & $11(14 \%)$ & $7(9 \%)$ & $3(43 \%)$ & $3(27 \%)$ & .388 \\
\hline $\begin{array}{l}\text { Organic brain } \\
\text { disease }\end{array}$ & $3(4 \%)$ & $8(10 \%)$ & 0 & 0 & .227 \\
\hline $\begin{array}{l}\text { Physical } \\
\text { disorders }\end{array}$ & $5(6 \%)$ & $8(10 \%)$ & $1(13 \%)$ & $1(20 \%)$ & .549 \\
\hline $\begin{array}{l}\text { Violence to } \\
\text { self/others }\end{array}$ & 0 & $3(4 \%)$ & 0 & 0 & .250 \\
\hline $\begin{array}{l}\text { Embarrassing } \\
\text { behaviour }\end{array}$ & 3 & $4(5 \%)$ & 0 & 0 & 1.000 \\
\hline Distress & 4 & $5(6 \%)$ & 0 & 0 & 1.000 \\
\hline \multicolumn{6}{|l|}{ Social problems } \\
\hline $\begin{array}{l}\text { Personal } \\
\text { Cleanliness }\end{array}$ & $2(3 \%)$ & $4(5 \%)$ & $1(25 \%)$ & $1(50 \%)$ & .625 \\
\hline Shopping & $3(4 \%)$ & $6(7 \%)$ & $1(17 \%)$ & $1(33 \%)$ & .453 \\
\hline $\begin{array}{l}\text { Cooking/ } \\
\text { getting meals }\end{array}$ & $4(5 \%)$ & $7(9 \%)$ & $1(13 \%)$ & $1(25 \%)$ & .508 \\
\hline $\begin{array}{l}\text { Household } \\
\text { chores }\end{array}$ & $4(5 \%)$ & $5(6 \%)$ & $1(20 \%)$ & $1(25 \%)$ & 1.000 \\
\hline Public transport & $3(4 \%)$ & $8(10 \%)$ & 0 & 0 & .227 \\
\hline Public amenities & $7(9 \%)$ & $3(4 \%)$ & 0 & 0 & .344 \\
\hline Education & $8(19 \%)$ & $11(14 \%)$ & $3(38 \%)$ & $3(27 \%)$ & .581 \\
\hline $\begin{array}{l}\text { Occupational } \\
\text { skills }\end{array}$ & $3(4 \%)$ & $13(16 \%)$ & 0 & 0 & .213 \\
\hline $\begin{array}{l}\text { Social } \\
\text { interaction }\end{array}$ & $3(4 \%)$ & $3(4 \%)$ & 0 & 0 & 1.000 \\
\hline $\begin{array}{l}\text { Management } \\
\text { of money }\end{array}$ & $1(1 \%)$ & $4(5 \%)$ & 0 & 0 & .375 \\
\hline $\begin{array}{l}\text { Management of } \\
\text { affairs }\end{array}$ & $4(5 \%)$ & $5(6 \%)$ & $1(20 \%)$ & $1(25 \%)$ & 1.000 \\
\hline $\begin{array}{c}\text { Decision } \\
\text { making }\end{array}$ & $2(3 \%)$ & $1(1 \%)$ & 0 & 0 & 1.000 \\
\hline
\end{tabular}

